\title{
Does a Renal Vascular Variation in the Renal Allograft Determine the Outcome of Renal Transplantation? Experience from the National Kidney Transplantation Center, Ethiopia
}

\author{
Habtamu Wondmagegn (D)', Abinet Gebremickael (D)', Mala George ${ }^{2}$, Teshale Fikadu (D) ${ }^{3}$, \\ Tadiwos Hailu Zewdie ${ }^{4}$, Tsegazeab Ayele (D)', Mahteme Bekele Muleta $\mathbb{D}^{5}$ \\ 'Department of Anatomy, College of Medicine and Health Sciences, Arba Minch University, Arba Minch, Ethiopia; ${ }^{2}$ Department of Biomedical \\ Sciences, Arba Minch University, Arba Minch, Ethiopia; ${ }^{3}$ School of Public Health, Epidemiology and Biostatistics Unit, Arba Minch University, Arba \\ Minch, Ethiopia; ${ }^{4}$ Department of Internal Medicine, Arba Minch University, Arba Minch, Ethiopia; ${ }^{5}$ Department of Surgery, Saint Paul Hospital \\ Millennium Medical College, Addis Ababa, Ethiopia \\ Correspondence: Abinet Gebremickael, Department of Anatomy, College of Medicine and Health Sciences, Arba Minch University, Arba Minch, \\ Ethiopia, Email abinetgebremickael@gmail.com; abinet.gebremickael@amu.edu.et
}

\begin{abstract}
Purpose: Renal vascular anatomy is known for presenting a wide range of variations. Kidneys with variant renal vascular anatomy, when used as a graft, appear to have a potential risk that could impair the outcome of kidney transplantation. Information on renal vascular variation and its implication in the surgical outcome of renal transplantation has not been well studied. The present study was aimed at evaluating the outcome of transplantation of renal allografts with variant renal vasculature as compared to allografts without renal vascular variation in the national kidney transplantation center of Ethiopia.
\end{abstract}

Patients and Methods: A health institution-based retrospective cohort study was conducted. A retrospective review of the medical records of kidney recipients was performed. A total of 120 renal transplant recipients' medical records were evaluated. A chi-square test and independent $t$-test were used to compare the surgical outcomes of renal transplantation. Graft survival was expressed using Kaplan-Meier curves and was compared using the log rank test. P-values less than 0.05 were considered statistically significant.

Results: Evaluation of the renal transplant outcomes has shown that the operation time and the length of hospital stay were significantly longer among recipients of allografts with variant vasculature than those with single renal vasculature. However, no significant difference was seen in the postoperative complication rate, rate of delayed graft function (DGF), creatinine clearance levels at 1,6 , or 12 months postoperatively, and 1-year graft survival among recipients of allografts with and without renal vascular variations.

Conclusion: No significant difference was noted in the overall outcome of transplantation of renal allografts with and without vascular variations. Hence, renal allografts with vascular variations are safe to be recruited for transplantation, as shown in this study. Keywords: renal transplantation, variant renal vasculature, renal allograft, graft survival

\section{Background}

End-stage renal disease (ESRD) is diagnosed when the patient has reached a glomerular filtration rate (GFR) of less than $15 \mathrm{~mL} / \mathrm{min}^{1}{ }^{1}$ Renal replacement therapy (RRT) is required for ESRD. Hemodialysis, peritoneal dialysis, and transplantation are the three types of RRT. ESRD patients can be successfully treated with hemodialysis or peritoneal dialysis, but kidney transplantation is by far the best therapeutic choice for the vast majority of ESRD patients. ${ }^{2,3} \mathrm{Kidney}$ transplantation necessitates extensive preoperative preparation and careful kidney selection. The site for transplanting a kidney is in the iliac fossa of the greater pelvis. The renal artery and vein are joined to the external iliac artery and vein, respectively, and the ureter is sutured into the urinary bladder. ${ }^{4}$ The 5 -year survival rate of kidney transplantation is more than twice 
that of dialysis, regardless of whether the donor is alive or dead, and dialysis is three times more expensive. More kidney transplants are performed every day around the world as a result of the extended survival and improved quality of life they bring. ${ }^{5}$

Variation of the renal vascular anatomy has gained importance with the advent of renal transplantation as it is important in selecting the appropriate kidney (left or right) for procurement. These variations are accessory renal arteries, prehilar branching (early branching), and unusual branching of the renal artery. Venous variants include multiple renal veins, late confluence of renal vein, retroaortic and circumaortic renal veins. ${ }^{6}$ Accessory renal arteries have immense importance during the transplantation, as failure of anastomosing them might lead to necrosis of a segment of the kidney and may require a surgeon to discard of the graft. ${ }^{7}$ Moreover, during the renal transplantation procedure, renal artery incision should be done $1.5-2 \mathrm{~cm}$ distal from the aortic origin to provide an easier hemorrhage control and to make anastomosis suitable. As a result, determining any possible early branching of the main renal artery is critical. Retroaortic left renal veins may have a high number of lumbar retroperitoneal tributaries, forming complex retroaortic systems, which can be easily injured during surgical dissection. ${ }^{8}$ Multiple renal veins may require the need to change the standard surgery protocol for renal transplantation and aneurysm resection. In the case of the circumaortic left renal vein, sometimes the posterior limb is not acknowledged before surgery and the renal vein seems to be normal looking, in which case the surgeon might injure the posterior limb. ${ }^{8}$

Kidneys with variant vasculature are prevalent in the general population (between $18 \%$ and $50 \%$ ). ${ }^{5,6,8}$ Worldwide, more than 100,000 kidney transplantations are performed each year. ${ }^{9}$ Owing to the scarcity of donor kidneys and the rising frequency of end-stage renal disease (ESRD), there is a global trend toward approving the so-called extended criteria kidney donors. Transplantation of renal allograft with vascular variations necessitates a sophisticated vascular reconstruction and anastomosis. Because renal vascular variations in kidney donors are linked to greater surgical complication rates in both the donor and recipient, recruiting renal allograft with variant vasculature for transplantation is considered as an expanded criterion. ${ }^{10}$

Some studies have linked the extensive dissection and back-table reconstruction to an elevated risk that could compromise the renal transplantation outcome. ${ }^{11,12}$ In addition, transplanting kidneys with arterial and venous variations is thought to have several disadvantages, such as prolonged warm ischemia duration; an increased incidence of acute tubular necrosis, which can increase the risk of acute rejection episodes, prolonged hospitalization; and poorer graft function. ${ }^{11}$ Consequently, even though kidneys with vascular variation are common in the general population, the kidney with simple vascular anatomy (ideally one artery, one vein) is often chosen for transplantation since the technical components of the process are usually completed without difficulties. ${ }^{13-15}$ However, there is a dearth of literature that has assessed and reported the outcomes of transplantation of a renal allograft with a variant vasculature in Ethiopia.

In Ethiopia, the first kidney transplantation took place in $2015 .{ }^{4}$ Since then, the practice of kidney transplantation in the country has shown steady expansion and progress. Given the rising number of kidney transplantation procedures, and the renal vascular variations that are common in the general population, renal allografts with variant vasculature are considered for transplantation. Otherwise, a significant number of kidney donors will not be entitled to donate a kidney if they have a variant renal vasculature; this may worsen the shortage of kidneys for transplantation. Hence, it has become important at this point to evaluate the outcome of transplantation of a renal allograft with a variant vasculature. The finding of the present study will advance the available information on the association between renal vascular anatomy and its transplantation outcomes.

\section{Patients and Methods}

This is a retrospective analysis of data from a prospectively maintained database from January 2015 to December 2020 of all patients undergoing live related renal allograft transplant at the national kidney transplantation center (NKTC), St. Paul's Hospital Millennium Medical College (SPHMMC), located in Addis Ababa, Ethiopia. The total number of transplantations performed in the institution from 2015 to 2020 was 142. Of these, 22 of them had incomplete relevant information in their medical record; hence, this study was carried out on a total of 120 recipients who underwent kidney transplantation in the transplantation center. Donor demographic details, CT angiography findings and intraoperative details were recorded. The side of donor nephrectomy was decided on the basis of the principle of leaving the better 
functioning kidney with the donor and choosing the kidney with the least complicated vascular anatomy. Standard guidelines for work-up of donor and recipient were followed. In current study, renal transplantations were grouped into two (86 recipients of kidneys with normal renal vascular allograft and 34 recipients of kidneys with grafts with complex vascular anatomy). Recipients of renal allografts with single, hilar renal arteries and single vein were considered as normal vascular allograft recipients; there were 86 patients in this group. Whereas recipients of renal grafts with accessory renal artery, early branching renal artery, accessory renal veins, late confluence of renal vein, retroaortic left renal vein, and circumaortic left renal vein were considered as variant vascular allograft recipients; there were 36 patients in this group.

\section{Immunosuppression Protocol}

All patients operated on in the center received conventional immunosuppressive protocols consisting of a calcineurin inhibitor (Tacrolimus), adjunctive agents (MMF), corticosteroid (prednisolone), with possible addition of antibody induction (Simulect /Basiliximab) or ATG.

\section{Donor and Recipient Surgery}

All donor nephrectomies were left side, and all patients underwent open donor nephrectomy except the first 42 patients who underwent hand assisted laparoscopic donor nephrectomy, due to lack of resource to sustain the laparoscopic surgery. All recipient surgeries used the external iliac vein and external iliac artery for vascular constructions, ureter to bladder anastomosis over a double $\mathrm{j}$ stent using the Lich-Gregoir technique. Kidney was implanted preferentially in the right iliac fossa irrespective of the side of donor nephrectomy. Different combination of anastomosis was performed in patients with complex anatomy renal grafts according to the recipient vascular anatomy and vascular anatomy of graft kidney. In majority of cases, main renal artery with accessory or polar arteries were anastomosed to external iliac artery in an end to side fashion or internal iliac artery in an end to end fashion.

\section{Outcome Measures}

Surgical outcome measures of renal transplantation include postoperative serum creatinine level at day 7, 1st, 6th, and 12th months, operative time, complications, length of stay (from postoperative day one to the day of discharge), 30-day readmission rate, reoperation rate, immediate graft function (IGF), delayed graft function (DGF) and poor early graft function (PEGF) rates. Immediate graft function (IGF) was defined as serum creatinine below $3 \mathrm{mg} / \mathrm{dl}$ when measured on the 1st postoperative week and no need for dialysis. Delayed graft function (DGF) was defined as the need for hemodialysis on postoperative days 1-7. Slow graft function (SGF) was defined as postoperative day 5 serum creatinine $\geq 3 \mathrm{mg} / \mathrm{dL}$ without the need for hemodialysis on postoperative days 1-7. Graft loss was defined as the return to permanent dialysis or death. Complications were classified as vascular (bleeding, hematoma, thrombosis, stenosis), ureteral (stricture, leak), and others (lymphocele, wound dehiscence, infection). Total operative time of donors is an operative time measured from the first incision to the last skin suture.

\section{Statistical Analysis}

The collected data were coded, cleaned, and entered into Epi-data version 4.4 and exported to SPSS version 25 for analysis. Variables were described as frequency, percentages, mean, and standard deviation (SD). Chi-square test was used for comparison of categorical variables whereas independent $t$-test was used for the comparison of continuous variables. Graft survival was expressed using Kaplan-Meier curves and was compared using the log rank test. Statistical significance was declared at $\mathrm{P}<0.05$. Results were presented using tables, figures, and text.

\section{Results}

\section{Baseline Characteristics of Kidney Transplantation Recipients}

Among a total of 120 recipients, 86 (71.6\%) were males, with a mean age of 33.3 years (SD \pm 11.41$) ; 34$ (28.3\%) recipients received renal allografts with renal vascular variations. Of the 34 recipients who received a kidney with variant vasculature, 
Table I Baseline Characteristics of Kidney Transplantation Recipients at NKTC, SPHMMC, 20I5-2020

\begin{tabular}{|c|c|c|c|c|c|}
\hline \multicolumn{2}{|c|}{ Recipient Characteristics } & $\begin{array}{l}\text { All } \\
\text { Recipients } \\
(n=\mid 20)\end{array}$ & $\begin{array}{l}\text { Recipients Receiving Allograft with } \\
\text { Normal Vascular Anatomy }(n=86)\end{array}$ & $\begin{array}{l}\text { Recipients Receiving Allograft with } \\
\text { Variant Vascular Anatomy }(n=34)\end{array}$ & P-value \\
\hline \multirow[t]{2}{*}{ Sex } & Male & $86(7 \mid .7)$ & $62(72.1)$ & $24(27.9)$ & 0.869 \\
\hline & Female & $34(28.3)$ & $24(70.6)$ & $10(29.4)$ & \\
\hline \multicolumn{2}{|c|}{ Age (mean $\pm S D)$} & $33.26 \pm 11.1$ & $32.9 \pm 10.8$ & $34.1 \pm 11.8$ & 0.608 \\
\hline \multicolumn{2}{|c|}{ BMI (mean \pm SD) } & $23.8 \pm 2.8$ & $23.5 \pm 2.8$ & $24.5 \pm 2.8$ & 0.087 \\
\hline \multirow[t]{2}{*}{ Relation } & Blood related & 105 & 76 & 29 & 0.646 \\
\hline & Spouse & 15 & 10 & 5 & \\
\hline \multicolumn{2}{|c|}{$\begin{array}{l}\text { Preoperative serum creatinine } \\
\text { (mean } \pm S D)\end{array}$} & $12.4 \pm 1.4$ & $12.6 \pm 1.5$ & $12.3 \pm 1.3$ & 0.199 \\
\hline \multicolumn{2}{|c|}{$\begin{array}{l}\text { Duration on hemodialysis } \\
\text { (months) (mean } \pm \mathrm{SD} \text { ) }\end{array}$} & $19.3 \pm 3$ & $19.4 \pm 3.2$ & $18.919 .4 \pm 2.5$ & 0.286 \\
\hline
\end{tabular}

28 (82.4\%) patients received an allograft with renal arterial variation, and $6(17.6 \%)$ patients received an allograft with renal venous variations. With regard to age, sex, and BMI, no significant difference $(\mathrm{P}>0.05)$ was noted between groups of patients who received renal allograft with anatomically variant renal vasculature and without (Table 1).

\section{Operative Parameters and Allograft Outcomes of Recipients}

Operative time and length of hospital stay were significantly longer $(\mathrm{P}<0.05)$ among recipients of allografts with variant renal vasculature as compared to recipients of allografts without variant renal vasculature. Graft function measured by serum creatinine values at postoperative week 1 , first month, six months, and one year were not significantly different $(\mathrm{P}>0.05)$ between recipients of allografts with variant renal vasculature and without variant renal vasculature (Figure 1). Diuresis of the transplanted kidney on the operation table was achieved in $95 \%$ of the transplantations and did not significantly differ $(\mathrm{P}>0.05)$ based on the renal vascular anatomy; that is, between groups who received allografts with and without variant renal vasculature. Only two of the patients who received allografts without vascular variation and one patient who received an allograft with vascular variation needed dialysis during the first postoperative week; this is nearly

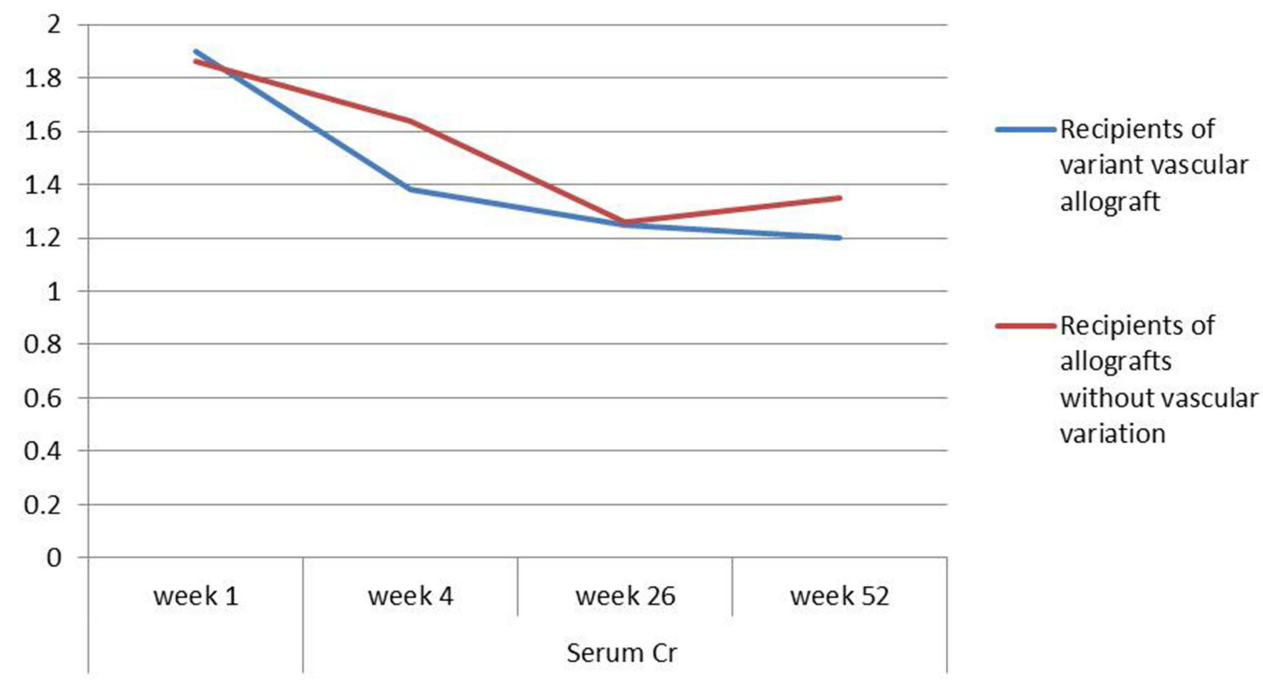

Figure I A line graph showing the mean postoperative serum creatinine level for recipients of allografts with and without vascular variations at NKTC, SPHMMC, 202I. 
Table 2 Intraoperative and Postoperative Outcome of Transplantation of Renal Allografts with and without Variant Vasculature at NKTC, SPHMMC, 2015-2020

\begin{tabular}{|c|c|c|c|c|c|}
\hline \multicolumn{2}{|l|}{ Variables } & $\begin{array}{l}\text { Recipients of Renal Allograft } \\
\text { Without Variant } \\
\text { Vasculature }(n=86)\end{array}$ & $\begin{array}{l}\text { Recipients of Allograft } \\
\text { with Variant Renal } \\
\text { Vasculature }(n=34)\end{array}$ & $\begin{array}{l}\text { Total } \\
(n=120)\end{array}$ & P-value \\
\hline \multicolumn{2}{|c|}{ Operative time, $\min ($ mean $\pm S D)$} & $150.8 \pm 25.3$ & $176.8 \pm 28.1$ & $158.18 \pm 28.5$ & $0.000 *$ \\
\hline \multicolumn{2}{|c|}{ Estimated blood loss $(\mathrm{mL})$ (mean $\pm \mathrm{SD})$} & $241.5 \pm 26.5$ & $246.6 \pm 29.4$ & $239.4 \pm 25.2$ & 0.180 \\
\hline \multicolumn{2}{|c|}{ Immediate graft function, $\mathrm{n}(\%)$} & $79(92.2)$ & $30(88.2)$ & $109(90.8)$ & 0.535 \\
\hline \multicolumn{2}{|c|}{ Slow graft function, n (\%) } & $5(5.8)$ & $3(8.8)$ & $8(6.7)$ & 0.551 \\
\hline \multicolumn{2}{|c|}{ Delayed graft function, $\mathrm{n}(\%)$} & $2(2.3)$ & I (2.9) & $3(2.5)$ & 0.136 \\
\hline \multicolumn{2}{|c|}{ Day 7 postoperative $\mathrm{Cr}, \mathrm{mg} / \mathrm{dl}($ mean $\pm \mathrm{SD})$} & $1.90 \pm 0.38$ & $1.86 \pm 0.29$ & $1.99 \pm 0.54$ & 0.081 \\
\hline \multicolumn{2}{|c|}{ Ist month postoperative $\mathrm{Cr}, \mathrm{mg} / \mathrm{dl}($ mean $\pm \mathrm{SD})$} & $1.38 \pm 0.3$ & $1.64 \pm 0.6$ & $1.39 \pm 0.34$ & 0.072 \\
\hline \multicolumn{2}{|c|}{ 6th month postoperative $\mathrm{Cr}, \mathrm{mg} / \mathrm{dl}$ (mean $\pm \mathrm{SD}$ ) } & $1.25 \pm 0.4$ & $1.26 \pm 0.2$ & $I .4 I \pm 0.67$ & 0.881 \\
\hline \multicolumn{2}{|c|}{ I year postoperative $\mathrm{Cr}, \mathrm{mg} / \mathrm{dl}($ mean $\pm \mathrm{SD})$} & $1.20 \pm 0.3$ & $1.35 \pm 0.6$ & $1.23 \pm 0.4$ & 0.078 \\
\hline \multirow{2}{*}{$\begin{array}{l}\text { Diuresis after } \\
\text { reperfusion }\end{array}$} & Achieved & $82(95.3)$ & $32(94.1)$ & II 4 (95) & $0.78 \mathrm{I}$ \\
\hline & Not achieved & $4(4.6)$ & $2(5.9)$ & $6(5)$ & \\
\hline \multicolumn{2}{|c|}{ Postoperative complications } & $6(6.9)$ & $5(14.7)$ & II (9.I) & 0.186 \\
\hline \multicolumn{2}{|c|}{ LOS, days (mean \pm SD) } & $12.34 \pm 0.9$ & $14.35 \pm 3.5$ & $12.3 \pm 2.4$ & $0.000 *$ \\
\hline \multicolumn{2}{|c|}{30 day re-admission, $\mathrm{n}(\%)$} & $3(3.5)$ & $2(5.8)$ & $5(4.1)$ & 0.572 \\
\hline \multicolumn{2}{|c|}{ Re-operation, n (\%) } & $2(2.3)$ & 0 & $2(1.6)$ & 0.369 \\
\hline
\end{tabular}

Note: *Shows statistically significant.

a similar rate between groups. Although not significant $(\mathrm{P}>0.05)$, postoperative complications were more frequently reported in patients who received grafts with variant renal vascular anatomy than without. Re-admission and re-operation rates were similar between the groups (Table 2).

\section{Graft Survival}

Postoperative graft survival was analyzed at 1 week, 1 month, 6 months and 1 year (Figure 2). The 1-year graft survival for 86 patients who received grafts without vascular variations was $95.4 \%$, and that for the 34 patients who received grafts with vascular variations was $91.2 \%$. The results showed that the variation of renal vascular anatomy is not a determinant of graft survival $(\mathrm{P}=0.378)$ (Figure 2).

\section{Discussion}

During the time of organ harvest, it is crucial for the kidney procurement team to consider significant vascular anatomical variations. Grafts with anatomic variations, such as double ureters and multiple renal vessels, present a challenge to transplant surgeons in both living and deceased donor transplants because these vessels are smaller in diameter and anastomosing them is difficult and time consuming, ${ }^{17-21}$ resulting in longer warm ischemia time and a higher incidence of delayed graft function. According to a systematic review and meta-analysis, ${ }^{7}$ the mean warm ischemia time and rewarming time were longer in the multiple renal artery groups than in the single renal artery group, and there was a higher incidence of delayed graft function. It appears obvious that performing multiple vascular anastomoses takes more time, which is likely to increase the rewarming time. Computed tomography angiography is an effective method for evaluating the renovascular morphology of the donor. ${ }^{20}$ The purpose of this study was to evaluate the outcomes of transplantation of renal allografts with variant renal vasculature as compared to allografts without renal vascular variation in the national kidney transplantation center of Ethiopia. 


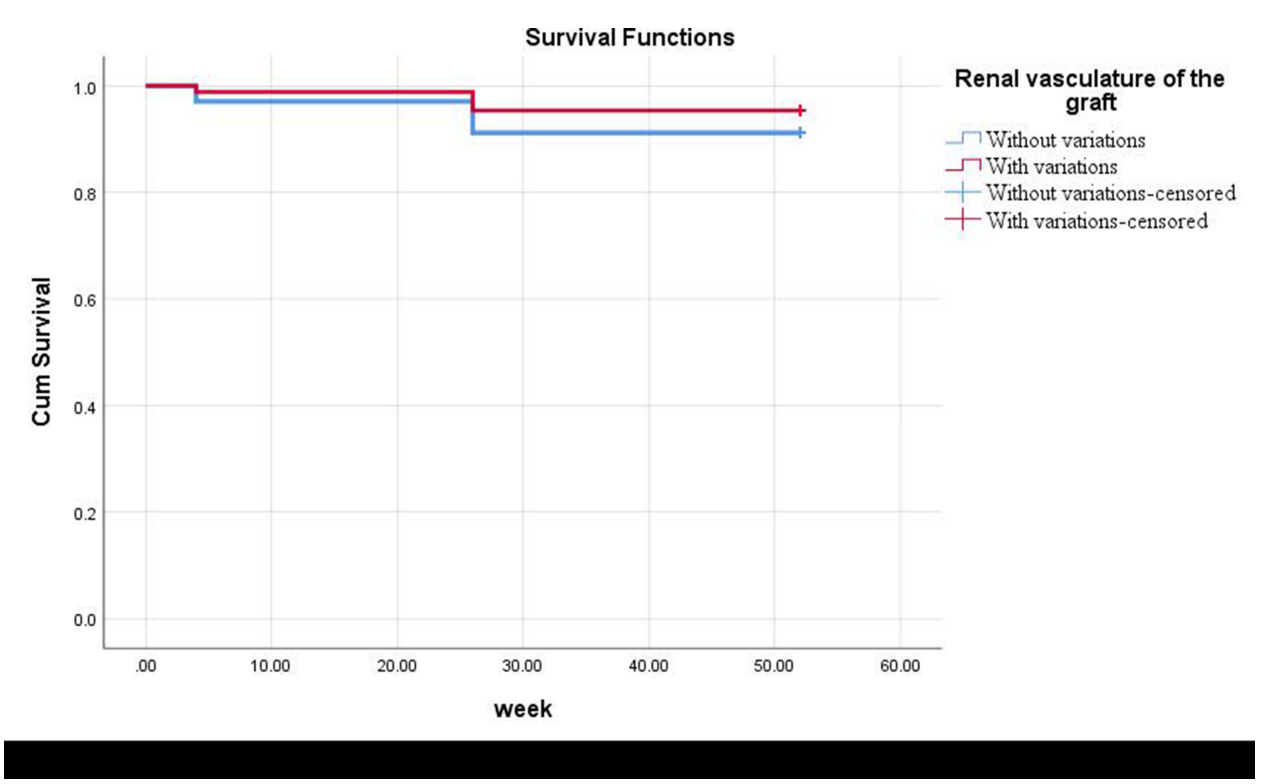

Figure 2 Kaplan-Meier analysis of estimated graft survival based on renal vascular anatomy of the graft. ( $\mathrm{P}=0.378$ using the log rank test (Mantel-Cox).)

Evaluation of the renal transplant outcomes did not show a significant difference in the postoperative complication rate, rate of delayed graft function (DGF), serum creatinine levels at 1, 6, or 12 months postoperatively, and 1-year graft survival among recipients of allografts with and without renal vascular variations. However, operation time and the length of hospital stay were significantly longer among recipients of allografts with variant vasculature.

In the present study, $34(28.3 \%)$ renal transplantations were performed using renal allografts with variant vasculature. All the renal allografts $(100 \%)$ that have been used for the transplantations carried out in the center were left kidneys. The practice of selecting left-sided grafts is not uncommon and has been reported in several studies. ${ }^{16-18}$ Furthermore, previous studies have commented on an increased risk of early graft failure with transplanting right-sided renal allografts. ${ }^{19}$ However, most meta-analyses today show that only $20-30 \%$ of LDNs are right-sided and there are still high-volume centers which practically do not perform RLDNs at all. ${ }^{21}$ In contrast, some centers have used a large number of right-sided renal allografts and reported no significant difference in graft function. ${ }^{22}$ The preference of left-sided renal allografts is often due to the longer left renal vein, which makes vascular anastomosis technically easier and has also been shown to decrease operating time. ${ }^{22}$

Postoperative serum creatinine level is an important measure of the outcome of renal transplantation. The present study has shown that the postoperative serum creatinine level values recorded at postoperative week 1, first month, sixth months, and one year were not significantly different between recipients of allografts with and without variant renal vasculature. This finding supports the reports of Ashraf et al and Basaran et al, who also declared no significant difference in the serum creatinine values at one, two, or five years between recipients of allografts with and without renal vascular variations..$^{17,23}$

A comparatively higher postoperative complication rate was registered (14.7\%) among recipients of allografts with variant renal vasculature; however, the difference was statistically insignificant compared to recipients of allografts without variant renal vasculature (6.9\%). Similar to this finding, a study by Hsu et al also did not see a difference in intraoperative and postoperative complication rates in a series comparing 277 allografts with normal vascular anatomy and 76 with variant vasculature. ${ }^{24}$ However, Carter et al found a small increase in ureteral complications among recipients with vascular variant graft. ${ }^{25}$

Diuresis of the transplanted kidney on the operation table is another important parameter of successful renal transplantation. In the current study, $95 \%$ of the transplanted allografts could have produced urine immediately after reperfusion. There was no significant difference noted between the groups on the rate of diuresis after reperfusion. In line with this finding, Lafranca et al reported no significant differences in the occurrence of diuresis of the transplanted kidney on the operation table $(\mathrm{P}=0.735) .{ }^{26}$ Moreover, a study by Asuri Krishina et al showed that the mean urine 
output postoperative day 1 and postoperative day 7 was not significantly different between recipients of complex vascular allografts and simple vascular allografts. ${ }^{27}$ Similarly, Kok et al reported that urine production within one hour of reperfusion was $91 \%$ for single artery allograft recipients and $92 \%$ for multiple artery allograft recipients $(\mathrm{P}=0.639){ }^{28}$

In the present study, operation time and the length of hospital stay were significantly longer among recipients of renal allografts with variant vasculature. In contrast to this finding, several other studies have reported that operation time and length of hospital stay were shorter and not significantly different among recipients of allografts with and without vascular variation. ${ }^{16,26,28}$ The longer operation time reported in this study may be due to the open approach of the donor nephrectomy procedure employed in the transplantation center as this procedure is performed simultaneously with the transplantation surgery. Open donor nephrectomy takes a longer operation time as compared to laparoscopic nephrectomy. ${ }^{18}$ Despite a statistically significant difference noted in the operation time and length of hospital stay, the clinical impact of these parameters is limited. ${ }^{16}$ Estimated blood loss, 30-day readmission, and reoperation rates were not significantly different with the renal vascular variations of the renal allograft, and this finding is supported by many other authors. ${ }^{26-28}$

The 1-year graft survival rate was nearly unaffected by the renal vascular anatomy in this study and was greater than $90 \%$ in both groups. The grafts without vascular variations had better graft survival at different points of measurement, but the difference was not statistically significant $(\mathrm{P}=0.378)$. This finding is consistent with graft survival rates reported in various previous studies. The study by Hsu et al analyzed 76 recipients of variant vascular grafts and reported a 1-year graft survival rate of $93.4 \% .{ }^{24}$ Similarly, Desai et al retrospectively reviewed 27 recipients of renal allograft with multiple renal arteries and reported an overall graft survival rate of $92.6 \% .{ }^{29}$

\section{Limitations of the Study}

This study might have information bias intrinsic to the retrospective design. In addition, though the study included all the cases from the period of the commencement of the first renal transplantations in Ethiopia from September 2015 to August 2020 in the center, there were still less cases.

\section{Conclusion}

Transplantation of renal allografts with and without renal vascular variations has comparable outcomes as those in the present study. Although operation time and length of hospital stay were significantly different between the groups, their clinical relevance is minimal. Hence, renal allografts with vascular variations are safe to be recruited for transplantation, and the entitlement of such allografts will increase the availability of kidneys for renal transplantations.

\section{Abbreviations}

AMU, Arba Minch University; BMI, Body mass index; Cr, Creatinine; DGF, Delayed graft function; ESRD, End-stage renal disease; LOS, Length of stay; NKTC, National kidney transplantation center; POD, Postoperative day; SD, Standard deviation; SPHMMC, St. Paul's hospital millennium medical college; SPSS, Statistical Package for the Social Sciences.

\section{Data Sharing Statement}

All the datasets used and/or analyzed during the current study are available from the corresponding author on reasonable request.

\section{Ethics Approval and Consent to Participate}

This study was carried out after obtaining ethical approval from Arba Minch University institutional research ethics review board/IRB (Ref. no: IRB/552/12; Issue date: 26/11/2020) and permission from SPHMMC to use the information in databases. As the study design was a retrospective review of medical records, the need for consent to participate was waived by an ethics committee. Moreover, no personal identifiers were used in the study. All kidney donors provided 
informed consent, in accordance with the Declaration of Istanbul. This study was conducted per the Declaration of Helsinki.

\section{Acknowledgments}

The authors acknowledge Arba Minch University, College of Medicine and Health Sciences for funding this study. We also would like to acknowledge SPHMMC for giving us permission to conduct this study in the center.

\section{Author Contributions}

All authors contributed to data analysis, drafting or revising the article, have agreed on the journal to which the article will be submitted, gave final approval of the version to be published, and agree to be accountable for all aspects of the work.

\section{Funding}

The current study was monetarily supported by Arba Minch University.

\section{Disclosure}

All authors have contributed significantly to the manuscript and declare that the work is original and has not been published elsewhere. None of the authors have any conflicts of interest.

\section{References}

1. Fauci A, Braunwald E, Kasper D. Harrison Principles of Internal Medicine 18th Edn Ed. New York NY: McGraw Hill Medical; 2015.

2. Meier-Kriesche HU, Schold JD, Srinivas TR, Reed A, Kaplan B. Kidney transplantation halts cardiovascular disease progression in patients with end-stage renal disease. Am J Transplant. 2004;4(10):1662-1668. doi:10.1111/j.1600-6143.2004.00573.x

3. Davis CL, Delmonico FL. Living-donor kidney transplantation: a review of the current practices for the live donor. J Am Soc Nephrol. 2005;16 (7):2098-2110. doi:10.1681/ASN.2004100824

4. Getachew S. Medical outcome of renal allograft donors at National kidney transplant center-Saint Paul's Hospital Millennium Medical College, Addis Ababa, Ethiopia. Ethiop Med J. 2020. Avalable from: https://www.emjema.org/index.php/EMJ/article/view/1537. Accessed January 23, 2022.

5. Sarier M, Yayar O, Yavuz A, Turgut H, Kukul E. Update on the management of urological problems following kidney transplantation. Urol Int. 2021;1-7. doi:10.1159/000512885

6. Gebremickael A, Afework M, Wondmagegn H, Bekele M. Renal vascular variations among kidney donors presented at the national kidney transplantation center, Addis Ababa, Ethiopia. Transl Res Anat. 2021;25:100145. doi:10.1016/j.tria.2021.100145

7. Bachul PJ, Osuch C, Chang ES, et al. Crossing anatomic barriers-transplantation of a kidney with 5 arteries, duplication of the pyelocalyceal system, and double ureter. Cell Transplant. 2017;26(10):1669-1672. doi:10.1177/0963689717722169

8. Brener BJ, Darling RC, Frederick PL, Linton RR. Major venous anomalies complicating abdominal aortic surgery. Arch Surg. 1974;108 (2):159-165. doi:10.1001/archsurg.1974.01350260019004

9. Global observatory on donation and transplantation: kidney transplants; 2019. Available at: http://wwwtransplantobservatoryorg/countkidney/. Accessed January 18, 2022.

10. Ahmadi AR, Lafranca JA, Claessens LA, et al. Shifting paradigms in eligibility criteria for live kidney donation: a systematic review. Kidney Int. 2015;87(1):31-45. doi:10.1038/ki.2014.118

11. Zorgdrager M, Krikke C, Hofker SH, Leuvenink H, Pol RA. Multiple renal arteries in kidney transplantation: a systematic review and meta-analysis. Ann Transplant. 2016;21(469):10.12659. doi:10.12659/AOT.898748

12. Nogueira JM, Haririan A, Jacobs SC, et al. The detrimental effect of poor early graft function after laparoscopic live donor nephrectomy on graft outcomes. Am J Transplant. 2009;9:337-347. doi:10.1111/j.1600-6143.2008.02477.x

13. Famurewa O, Asaleye C, Ibitoye B, Ayoola O, Aderibigbe A, Badmus T. Variations of renal vascular anatomy in a nigerian population: a computerized tomography study. Niger J Clin Pract. 2018;21(7):840-846. doi:10.4103/njcp.njcp_237_17

14. Salih MA, Hasan MA. Renal artery morphology and anatomical variations among Sudanese subjects. Anat J Afr. 2018;7(1):1103-1112. doi:10.4314/aja.v7i1.169482

15. Raman SS, Pojchamarnwiputh S, Muangsomboon K, Schulam PG, Gritsch HA, Lu DS. Surgically relevant normal and variant renal parenchymal and vascular anatomy in preoperative 16-MDCT evaluation of potential laparoscopic renal donors. Am J Roentgenol. 2007;188(1):105-114. doi:10.2214/AJR.05.1002

16. Cooper M, Kramer A, Nogueira JM, Phelan M. Recipient outcomes of dual and multiple renal arteries following 1000 consecutive laparoscopic donor nephrectomies at a single institution. Clin Transplant. 2013;27(2):261-266. doi:10.1111/ctr.12062

17. Ashraf HS, Hussain I, Siddiqui AA, Ibrahim MN, Khan MU. The outcome of living related kidney transplantation with multiple renal arteries. Saudi J Kidney Dis Transplant. 2013;24(3):615. doi:10.4103/1319-2442.111087

18. Arpalı E, Karataş C, Akyollu B, Yaprak D, Günaydın B, Koçak B. Hand-assisted laparoscopic donor nephrectomy in kidneys with multiple renal arteries versus a single renal artery: an analysis of vascular complications from 1350 cases. Turkish J Urol. 2020;46(4):314-319. doi:10.5152/ tud.2020.19280 
19. Hsu JW, Reese PP, Naji A, Levine MH, Abt PL. Increased early graft failure in right-sided living donor nephrectomy. Transplantation. 2011;91 (1):108-114. doi:10.1097/TP.0b013e3181fd0179

20. Sarier M, Callioglu M, Yuksel Y, Duman E, Emek M, Usta SS. Evaluation of the renal arteries of 2144 living kidney donors using computed tomography angiography and comparison with intraoperative findings. Urol Int. 2020;2-5. doi:10.1159/000507796

21. Ozturk SA, Yuksel Y, Erbis H, et al. Laparoscopic live donor nephrectomy: experience of high-volume center with 2477 cases. Urol Int. $2020 ; 1-8$. doi:10.1159/000511377

22. Broudeur L, Karam G, Chelghaf I, et al. Feasibility and safety of laparoscopic living donor nephrectomy in case of right kidney and multiple-renal artery kidney: a systematic review of the literature. World J Urol. 2019;38(4):1-9.

23. Başaran Ö, Moray G, Emiroğlu R, Alevli F, Haberal M, editors. Graft and patient outcomes among recipients of renal grafts with multiple arteries. Transplantation proceedings. Elsevier; 2004.

24. Hsu TH, Su L, Ratner LE, Trock BJ, Kavoussi LR. Impact of renal artery multiplicity on outcomes of renal donors and recipients in laparoscopic donor nephrectomy. Urology. 2003;61(2):323-327. doi:10.1016/S0090-4295(02)02124-6

25. Carter JT, Freise CE, McTaggart RA, et al. Laparoscopic procurement of kidneys with multiple renal arteries is associated with increased ureteral complications in the recipient. Am J Transplant. 2005;5(6):1312-1318. doi:10.1111/j.1600-6143.2005.00859.x

26. Lafranca JA, van Bruggen M, Kimenai HJ, et al. Vascular multiplicity should not be a contra-indication for live kidney donation and transplantation. PLoS One. 2016;11(4):e0153460. doi:10.1371/journal.pone.0153460

27. Asuri Krishna UM, Jain M, Prakash O, et al. Outcomes of complex V/S simple vascular anatomy grafts following living donor renal transplant-experience from a Tertiary Care Center. Clin Nephrol Ren Care. 2020;6(2):4-6.

28. Kok NF, Dols LF, Hunink MGM, et al. Complex vascular anatomy in live kidney donation: imaging and consequences for clinical outcome. Transplantation. 2008;85(12):1760-1765. doi:10.1097/TP.0b013e318172802d

29. Desai MR, Ganpule AP, Gupta R, Thimmegowda M. Outcome of renal transplantation with multiple versus single renal arteries after laparoscopic live donor nephrectomy: a comparative study. Urology. 2007;69(5):824-827. doi:10.1016/j.urology.2007.01.026

Clinical Audit

Dovepress

\section{Publish your work in this journal}

Clinical Audit is an international, peer-reviewed, open access journal focusing on the processes and outcomes of clinical audit in any area of healthcare. All aspects of patient care are addressed within the journal and practitioners from all disciplines are invited to submit their work. Areas covered include: Publication of audits; How an audit has changed practice; Practical tips on how to do audits and to avoid pitfalls; How audits have changed patient care; Calls and justifications for new audits. The manuscript management system is completely online and includes a very quick and fair peer-review system, which is all easy to use. Visit http://www.dovepress.com/testimonials.php to read real quotes from published authors.

Submit your manuscript here: https://www.dovepress.com/clinical-audit-journal 